\title{
What Influences Salary: A Study Of MIS Faculty Job Offers
}

M. Pamela Neely, Rochester Institute of Technology

Thomas Tribunella, State University of New York at Oswego

Zhi Tang, Rochester Institute of Technology

Clyde E. Hull, Rochester Institute of Technology

\begin{abstract}
What matters when you're negotiating a job offer? We address this and other questions using data from the Association for Information Systems (AIS) Salary Surveys on compensation, rank, publication data, and similar data associated with MIS Faculty job offers. Our study has three primary findings. First, school and individual factors influence the position and salary offered, but individual factors have a stronger impact. Second, we find the position (i.e., associate/assistant professor and teaching load) offered by schools partially mediates the relationship between school and individual factors and the starting salary. Third, the direct impact of individual factors is also influenced by some school factors. Specifically, top tier publication is the most important individual factor in determining the salary level at PhD granting institutions.
\end{abstract}

Keywords: Management Information Systems, Compensation, Salary, Job Offers

\section{INTRODUCTION}

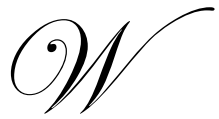

hat matters when you're negotiating a job offer? Three general categories seem relevant to the size of the offer made: The nature of the job, characteristics of the candidate, and characteristics of the potential employer. But which of these has the greatest effect? The answer to this question seems relevant and important to candidates and employers alike. Despite the value of an understanding of how job offers are shaped, relatively little is known about how offers are made. As is often the case in the absence of knowledge, rumor and superstition fills the gap. Our paper, by investigating the MIS faculty starting salary and its relevant factors, tries to provide some rationale for both MIS programs and job candidates in understanding and determining their job offers.

We interviewed several current and recent candidates, several faculty members who were representing or had recently represented their institution in the hiring process, and several senior administrators. In addition, we asked two MIS professionals to offer their opinions on the factors that would affect the salary offers of MIS faculty members. These professionals had had no direct interaction with any academic institution since receiving their degrees and entering the workforce, and had not been exposed to the conventional wisdom on the subject.

Interestingly, the academics at all levels offered similar views on what would shape MIS faculty salary offers, with several misconceptions being repeated often. Faculty members who had represented their school in the hiring process were inclined to list institutional or external factors first - e.g., whether the institution was researchoriented or teaching-oriented, whether it was private or public, whether it had a doctoral program, whether it was a union campus, and whether it was a good year for MIS. The consensus appeared to be that individual characteristics - particularly the candidate's accomplishments in terms of publishing A-level journal articles - might matter, but that the institutional characteristics overwhelmingly outweighed them. When asked, faculty members generally agreed that positional factors would also affect salary, but it was usually felt that individual factors (e.g., experience, A-level publications) would drive the positional ones. In addition, Larsen and Neely [2000] found that, although collegiality was the number one criteria when evaluating a potential faculty candidate at the assistant professor level, 
the number and quality of an applicant's journal publications was the third highest concern ${ }^{1}$. Given the perceived importance of this factor, it is not surprising that MIS academics believe that it would be a factor in shaping job offers.

The MIS professionals differed sharply from academics in that they listed individual characteristics first accomplishments, recommendations, and experience being three commonly-listed traits. These were typically listed in this order, and it is worth noting that the MIS professionals clearly indicated that they expected the candidate's accomplishments to be the primary driver of salary offers. Institutional/external factors and positional factors were not initially listed at all; when asked to comment on the importance of these general categories, the MIS professionals added them to the list, placing institutional factors below individual ones and positional factors below institutional ones.

Though this evidence is anecdotal, it does serve to illustrate a point: This disparity of opinion demonstrates that how MIS faculty salary offers are determined is not generally understood. As a proper understanding of the factors shaping the offers may help candidates and institutions better find appropriate matches, it seems beneficial to both sides to shed light on which traits have what effect on the salary offer. We thus intend to address the following three research questions:

1. Do individual factors, position-related factors, or external/institutional factors have the most effect on salary offers?

2. How do individual factors, position-related factors, and external/institutional factors characteristics interact to affect salary offers?

3. What factors moderate the relationship between salary and its most significant predictor?

In what follows, we develop hypotheses concerning these general categories of factors. We test these hypotheses using data from Professor Galleta's AIS website survey ${ }^{2}$, and based on our findings we present a model of the factors driving MIS faculty salary offers. Dennis [2006] has suggested that the structure of the promotion and tenure decisions in the MIS field may need to be revised; we hope that our contribution to the understanding of MIS faculty employment will help inform the discussion of the future of the MIS field.

\section{LITERATURE REVIEW AND CONTRIBUTIONS OF THIS STUDY}

\section{Literature Review}

This study extends the work that was published by Tribunella, Neely and Hull (2007), who analyzed the determinants of MIS salary offers by using two sets of factors: professor profile and school profile. This study extends the previous study by adding position factors and moderating variables. As indicated previously, the nature of the job, characteristics of the candidate, and characteristics of the potential employer, can potentially impact the size of a salary offer for a new faculty member. Using the data from the Galletta survey we will develop hypothesis and models. Based on our review of the literature, there may be some variables that are not currently being collected that may be of interest for further research. These additional factors are noted at the end of this section.

Formby and Hoover [2002] surveyed 207 academic institutions who were hiring economists during the 1997 - 1998 academic year. They looked at variables which predicted the probability of an applicant being hired into a tenure track position. These variables included whether a candidate was ABD or Ph.D, the productivity of the candidate's producing department (i.e. where they obtained their degree) and whether the hiring school was private or public. Not surprisingly, the probability of being offered a tenure track position was found to be greater for the candidate who has completed his or her Ph.D. than for the candidate who has not completed all of his or her requirements. Somewhat more surprising is that an offer from a public university had a higher probability of being a

\footnotetext{
${ }^{1}$ The applicant's teaching interest was the second highest concern. Larsen and Neely [2000] evaluated twenty characteristics in total.

${ }^{2}$ http://www.pitt.edu/ galletta/salsurv.html
} 
tenure track position than an offer from a private university. And, also not surprisingly, the probability of being offered a tenure track position rose in direct correlation to the research productivity of the producing department [Formby and Hoover, 2002]. Because the characteristics of the potential employer, as well as the characteristics of the candidate, are explored in the current study it is important to understand what factors are related to the probability of the offer being extended in the first place.

In a related study, Stock and Siegfried [2001] found that the school of origin is a factor in securing a full time position. Additionally, they found that the area of specialization and whether a candidate worked as a teaching or research assistant will impact the probability of hire. Higher salaries go to those who hed positions outside of academia before entering the ivory tower. Interestingly, the amount of time spent in the graduate program can also influence the starting salary.

Related to the issue of public vs. private institutions, Nagowski [2006] found that the average continuation rate for professors is higher at private institutions than it is at public universities. He also found that, all other things being equal, higher continuation rates will result from institutions with higher average compensation packages.

In the Human Resources Development domain Kirk [1996] found that four factors account for most of the variance in salary offers: faculty rank, reward structure, number of years of full time teaching experience, and the attainment of the doctorate degree.

Hobbs, Weeks, and Finch [2005] estimate the premium that must be paid when business school faculty lines become vacant. In the case of finance faculty, the average total premium to be paid to replace an existing faculty member is $\$ 9,653$. This average amount takes into account all replacement combinations, i.e. assistant replaced with assistant, assistant replaced with full, associate replaced with full, etc. The largest frequency of replacements is an assistant replaced with another assistant. Within this case, the average salary premium is $\$ 10,000$. Thus, even within the same rank, replacement of faculty incurs a cost above and beyond the search costs.

That this premium exists is not surprising, considering that several studies show that academic salaries have not been able to keep pace with inflation [Anonymous, 2005a, 2005b; Smallwood, 2005; Wilson, 2004; Zoghi, 2003]. Given this, it is not surprising that some studies show a salary inversion as faculty attain more senior ranks [Bratsberg, Ragan Jr, and Warren, 2003; Castle, 2005]. According to Bratsberg et al. [2003], many studies do not account for declining research productivity in senior faculty. Thus, although replacement costs of senior faculty may be high, it would be expected that new young faculty would be enthusiastic researchers with high productivity. On the other hand, senior faculty must take on additional service requirements that would impact the time available for research. These service requirements are a necessary component in the life of the institution and cannot be discounted.

Given the above, it would be interesting to obtain additional data in the Galletta survey. Currently there is no distinction between a candidate who is $\mathrm{ABD}$ and one who has completed his or her $\mathrm{PhD}$. This distinction may be more important as the job market shifts from an undersupply of candidates to an oversupply. Likewise, it would be interesting to capture data on the length of time that a candidate has been in pursuit of the degree. Although "years of teaching" is captured, this data is open for interpretation on the part of the candidate. Are they full time equivalent years? Or simply the number of years teaching? The adjunct who taught one class per semester for 10 years prior to pursuing a Ph.D. is different from the student who teaches one class a semester while also taking classes full time. Both are quite different from the individual who is switching jobs and has 4 years of full time experience in a tenure track position.

Within the limitations section we also list some additional data that would be interesting to see. These additional variables, if included in the Galletta survey, may help in future research on the question of what affects a job offer, particularly outside of the salary issue. 


\section{Contributions Of This Study}

This study is a follow-up to a paper that was published in 2007 by Tribunella, Neely and Hull. The Tribunella et al. (2007) paper examined professor profiles and school profiles. Here we extend the analysis by considering the influence that the candidate and the school will have on position factors as well as the salary offer. We also perform more sophisticated statistical analyses by testing three sets hypotheses, building three regression models, examining mediation test models, and completing moderation tests. This study contributes to the Tribunella et al. (2007) paper and the literature by extending the analysis and providing a deeper insight into how school factors, individual factors, position factors, and moderators interact to result in a salary offer. Both job candidates and administrators should find the results helpful in evaluating salary offers.

\section{HYPOTHESIS DEVELOPMENT}

\section{Which Category Of Factors Has The Greatest Impact?}

Our first research question asks which has the greatest impact on salary offers: institutional/external factors, individual factors, or positional factors. The majority of academics familiar with the process by dint of having gone through it as a candidate and, possibly, as an interviewer or administrator, suggested that institutional factors would be dominant. Institutions are bound by institutional norms both explicit and implicit, with organizational inertia and internal social pressure tending to keep new salaries similar to previous starting salaries. These norms are supplemented by restrictions on resources - some institutions may simply not be able to afford salaries that are well within the reach of others. Thus, there is considerable face validity to the hypothesis most consistent with the views of the academics we interviewed.

Hypothesis 1a: Institutional/external factors have the greatest impact on the salary associated with an offer of employment to a prospective MIS professor.

The MIS professionals we interviewed generally favored the individual candidate's characteristics, such as accomplishments and experience, as the most important driver of salary. Support for this category being important could be found among academics as well, who often listed publications or, more specifically, A-level publications, as a factor that would influence salary. Demonstrated ability to excel at the job should serve to make the candidate more desirable, strengthening the candidate's bargaining position and thus resulting in higher salary offers. High performers may also be expected to do more things (e.g., top researchers may bring in grant money; top teachers may take a more active role in student affairs), further justifying the higher salary. Thus, we find face validity in the hypothesis most consistent with the views of the MIS professionals we interviewed.

Hypothesis 1b: Individual factors have the greatest impact on the salary associated with an offer of employment to a prospective MIS professor.

While the characteristics of the position were not generally suggested as the most important factor in our interviews, an argument can be made for their importance. Some positions are associated with greater compensation than others (e.g., associate professors typically earn more than assistant professors). The nature of the responsibilities associated with the position (e.g., teaching load) should also impact the associated compensation. Thus, there exists some support for the following hypothesis.

Hypothesis 1c: Positional factors have the greatest impact on the salary associated with an offer of employment to a prospective MIS professor.

\section{How Do The Categories Interact?}

Our second research question asks how the general categories of factors interact with one another to affect the salary offered to prospective MIS professors. We identified two logical mediating relationships, both of which were also independently identified by the interviewees: positional factors are expected to mediate the relationships 
of both (1) individual and (2) institutional/external factors. Our rationale is that both school/external and individual factors shape the position that the candidates will get. Salary, as the compensation for a specific position, should be more closely related to position factors, but the position itself may be manipulated to bring the salary in line with the constraints of the individual and institutional traits. There was general agreement among both our academic and our professional interviewees on this point. Three faculty members with whom we spoke informed us that they themselves had accepted positions which had been changed to match their qualifications; two explicitly stated that this was done to allow them to receive a salary appropriate to his qualification. Published job openings often indicate an opening at the assistant/associate professor level, depending on the candidate's qualifications, suggesting that the practice is relatively common. Thus, there is considerable support for the following hypotheses:

Hypothesis 2a: Positional factors mediate the impact of institutional/external factors on salary.

Hypothesis 2b: Positional factors mediate the impact of individual factors on salary.

\section{What Moderates The Relationship Between Top-Tier Publications And Salary Offers?}

Our third research question asks about moderators to the relationship between salary and its most powerful predictor. After evaluating Hypotheses 1 and 2, we were able to identify this predictor as the candidate's top-tier publication record. We then identified four variables as potential moderators.

The market for MIS professors has changed significantly over the past 6 years. In 2000, there were approximately 4 jobs for every MIS faculty candidate (AIS placement website). By 2003 the trend was moving in the opposite direction and within the last year or so it has been 4 candidates for each job opening. Many schools are reporting that they are receiving $60-100 \mathrm{CV}$ s for a job opening. Thus, we would expect the shift from oversupply of jobs to oversupply of candidates to have an affect on the overall salary offer. Specifically, the importance of top tier publication for salary is lessening each year because of the oversupply of job candidates. This would cause a (negative) moderating effect on the importance of top-tier publications.

Hypothesis 3a: The relationship between top tier publications and salary is negatively moderated by the year of the job offer.

An institution with a Ph.D. program has the potential to be more focused on research than an institution without a Ph.D. program. Faculty need to have a research agenda and strong research capabilities in order to guide students within the Ph.D. program. In addition, faculty at Ph.D. granting institutions may be more likely to have research support in the form of graduate assistants and research funds. These additional resources, coupled with the research reputation of a $\mathrm{Ph}$. D. granting institution, may have an impact on the relationship between top tier publications and the salary offer. Specifically, institutions with Ph.D. program are willing to compensate more for top tier publications.

Hypothesis 3b: The relationship between top tier publications and salary is positively moderated by whether the institution making the offer has a Ph.D. program.

We expected unionized business schools to offer lower salaries than schools without a union. This is because non-union schools can react to market pressures and pay faculty commensurate with what they would earn in business. Union schools must have equity across all academic disciplines and cannot pay a premium for fields where salaries are generally higher. Thus the English professor and the Engineering professor and the MIS professor will all be paid on the same scale. Given this fact, it may or may not be possible to pay a premium for top tier publications. Specifically, a unionized offer compensates less for top tier publications.

Hypothesis 3c: The relationship between top tier publications and salary is negatively moderated by whether the institution making the offer is unionized. 
Based on the perceptions reported by our interviewees, we concluded that private institutions are generally perceived to offer higher salaries than public institutions. Public institutions are constrained by state budget cuts and other governmental funding issues. On the other hand, private institutions are tuition driven. More students means more tuition dollars, and more available resources. It could be argued that the prestige of faculty publishing in top tier publications would attract more students and thus more tuition dollars, increasing available resources and thus affecting the salary offer. Specifically, private schools are willing and able to compensate more for top tier publications.

Hypothesis 3d: The relationship between top tier publications and salary is moderated by whether the institution making the offer is private or public.

\section{METHODS}

\section{Sample}

The sample is drawn from the population of MIS professors who were looking for jobs between 2003 and 2006. The survey was designed and administered online through the AIS website by Professor Dennis Galleta of the University of Pittsburgh to new professors and professors changing jobs during this time. Respondents were not obliged to fill out the survey, suggesting that there may be a self-selection bias [Judd, et al., 1991].

However, the survey design appears to minimize this difficulty. In addition to being entirely voluntary, the survey makes revealing one's identity (to Professor Galleta only) optional, meaning that the data is effectively anonymous. $47 \%$ of respondents chose to reveal their identities (to Professor Galleta), and no significant differences between the anonymous and identity-revealed respondents were found, except that the cases with identity revealed have offers from schools that require a greater number of A publications than the cases with identity code " 0 ". This difference is significant at the .05 level. Furthermore, a comparison of survey respondent salaries (the most sensitive information in the survey) with salary data provided by the Association to Advance Collegiate Schools of Business (AACSB) suggests that the survey data is consistent with the archival data. 182 cases were collected. After listwise deletion of the missing value cases, the sample size was 95. We used ANOVA to test if there was any significant difference between the final sample and the cases deleted for missing values. No missing-value bias was identified in our key variables such as salary, personal publication record, school tenure requirements, union, and private. However, more missing cases were from earlier years: 4.02 as the mean of the survey year in missing case versus 4.41 as the mean of the survey year in the final sample ( $t$ test is significant at the .05 level). Therefore, appropriate adjustment is needed when interpreting pertinent conclusions.

\section{Measures}

All of the data used in this study is drawn from a single source, the online survey described above. As the variables to be measured were generally straightforward and objective in nature, multi-item measures were not used. All answers were provided in numerical form, with categorical data being coded (e.g., "2" for assistant professor, "3" for associate professor, etc.). However, the survey method may be subject to common methods variance. Therefore, even though multi-item measures are not applicable in this study, we assessed the potential common method bias by conducting Harmon's one factor test [Podsakoff and Organ, 1986]. The items that were used to measure both dependent and independent variables were entered into one exploratory factor analysis. In analyzing the covariance matrix, we found that the first factor accounted for only $26 \%$ of the total variance, which suggested that no single factor accounted for the majority of covariance; therefore, common method variance is not solely responsible for our findings. Thus, common method bias would not explain many interactive relationships between the predictor and outcome variables.

In keeping with our research question, we divide the pertinent variables that may affect the salary levels into three categories (please see Table 1 in the results section below). They are school-related or external factors, individual factors, and position-related factors. 
School-Related or External Factors include seven factors. Year is the year that the offer was made. It is a 4year period from 2003 to 2006. Suburban indicates the location of a school. "1" means that the school is in a suburban area and " 0 " means otherwise. Private is another dummy variable related to school characteristics. If a school is a private college, it is coded as "1"; otherwise is "0". Union describes if the faculty of the school are unionized. If yes, it is coded as "1"; otherwise it is " 0 ". We use Doctoral to describe if a school provides a doctoral degree. " 1 " means yes, and " 0 " means no. The last pair of variables is concerned with tenure requirements. Arequirement indicates how many top tier publications are needed for getting tenure at a school and Totalrequirement refers to how many total publications are needed for getting tenure.

Individual Factors describe the characteristics of the job candidates. A-pub shows how many top tier publications the candidate has at the time of the offer. Other-pub indicates how many publications the candidate has in journals that are other than top tier journals at the time of the offer. Teaching shows how many years the candidate has been teaching prior to receiving the offer.

Position-Related Factors are concerned with the characteristics of an offer. Course-load is the number of courses the candidate will be expected to teach in a year if the offer is accepted. We created a dummy variable Assistant and coded it as " 1 " if the offer was associated with an assistant professorship or as " 0 " if it was not. If the offer was associated with an associate professor position, the dummy variable Associate was coded as "1", otherwise as " 0 ".

The dependent variable is the Salary associated with the offer. We believe that salary is the most important part of an employee's compensation and that it should more or less reflect the level of other types of compensation. A histogram illustrated that Salary is generally normally distributed (skewness $=1.11$ ). Therefore, no logarithm transformation is needed.

\section{ANALYSIS}

The analysis is divided into three studies according to our research purpose. In Study 1, we enter school/external factors, individual factors, and position-related factors into regressions step by step. The purpose of this study is to find out which factors have the most impact on salary when all factors are present. Study 1 thus relates to our first research question and to hypotheses $1 \mathrm{a}, 1 \mathrm{~b}$, and $1 \mathrm{c}$.

Study 2 develops a set of regressions to test the mediating effect of position factors on the relationship between school/external and individual factors and salary, and thus addresses our second research question and hypotheses $2 \mathrm{a}$ and $2 \mathrm{~b}$. Analyzing the mediation effects involved three models [Gibson and Birkinshaw, 2004]. The first model was used to establish the relationship between the independent variable (here, school/external factors and individual factors) and the mediator (position factors). The second model was used to show that the independent variable (school/external factors and individual factors) influenced the dependent variable (salary). The third and final model examined whether the hypothesized mediator (position factors) influenced the dependent variable (salary) when the independent variables (school/external factors and individual factors) were included in the model. The changes of the magnitude and significance of the independent variable coefficients from the first model to the third model determined whether a full mediation model or a partial mediation model was appropriate.

Study 3 designs four sets of regressions to test the moderation effects of Year, Doctorate, Union, and Private on the relationship between A-pubs and salary. The purpose of Study 3 is to investigate the interaction effect of school/external factors and individual factors on salary. This study addresses our third research question and hypotheses $3 \mathrm{a}, 3 \mathrm{~b}, 3 \mathrm{c}$, and $3 \mathrm{~d}$. 


\section{RESULTS}

\section{Descriptive Statistics}

Table 1 summarizes the mean, standard deviations, and correlations of the involved variables. From Table 1 , we can see that salary is significantly higher in schools with doctorate programs $(\mathrm{r}=.55, \mathrm{p}<.001$, two-tailed test $)$ or in schools with higher requirements on tenure (A-requirement: $r=.57, \mathrm{p}<.001$, two-tailed test; Totalrequirement: $\mathrm{r}=.31, \mathrm{p}<.01$, two-tailed test). If the candidate has a top tier publication, chances are the compensation will be higher $(\mathrm{r}=.58, \mathrm{p}<.001$, two-tailed test $)$.

Table 1- Mean, Standard Deviation, and Pearson Correlation (r)

\begin{tabular}{|c|c|c|c|c|c|c|c|c|c|c|c|c|c|c|}
\hline & 1 & 2 & 3 & 4 & 5 & 6 & 7 & 8 & 9 & 10 & 11 & 12 & 13 & 14 \\
\hline Mean & $91,886.40$ & 4.41 & .48 & .22 & .19 & .32 & 1.38 & 6.33 & .87 & 3.64 & 3.98 & 5.09 & .62 & .11 \\
\hline Standard Deviation & $19,095.07$ & 1.13 & .50 & .42 & .39 & .47 & 1.72 & 2.67 & 1.42 & 4.54 & 3.73 & 1.61 & .49 & .31 \\
\hline \multicolumn{15}{|l|}{\begin{tabular}{|l|} 
Correlations: \\
\end{tabular}} \\
\hline 1. Salary & 1 & & & & & & & & & & & & & \\
\hline 2. Year & -.04 & 1 & & & & & & & & & & & & \\
\hline 3. Suburban & .12 & $.17^{\dagger}$ & 1 & & & & & & & & & & & \\
\hline 4. Prorate & -.09 & -.06 & -.06 & 1 & & & & & & & & & & \\
\hline 5. Union & -.08 & .16 & .07 & $-.19^{\dagger}$ & 1 & & & & & & & & & \\
\hline 6. Doctorate & $.55^{* * *}$ & -.01 & -.11 & -.14 & -.10 & 1 & & & & & & & & \\
\hline 7. A-requirement & $.57^{* * 3 *}$ & -.02 & .04 & -.12 & -.14 & $.63^{* * * *}$ & 1 & & & & & & & \\
\hline $\begin{array}{l}\text { 8. Total- } \\
\text { requirement }\end{array}$ & $.31^{* * *}$ & -.06 & -.01 & $-.18^{\dagger}$ & -.06 & $.37^{* * * *}$ & $.50^{* * * *}$ & 1 & & & & & & \\
\hline 9. A-pub & $.58^{* * *}$ & -.03 & -.03 & -.03 & -.11 & $.29^{* * *}$ & $.28^{* * *}$ & .06 & 1 & & & & & \\
\hline 10. Other-pub & .10 & -.01 & -.03 & -.09 & -.00 & .05 & -.02 & .08 & $.29^{* *}$ & 1 & & & & \\
\hline 11. Teaching & .12 & .06 & .00 & .05 & .13 & -.06 & $-.19^{\dagger}$ & -.13 & $.39^{* * * *}$ & $.69^{* * * *}$ & 1 & & & \\
\hline $\begin{array}{l}\text { 12. Course - } \\
\text { load }\end{array}$ & $-.57^{* * * *}$ & -.12 & -.01 & $.18^{\dagger}$ & $.18^{\dagger}$ & $-.56^{* * * *}$ & $-.50^{* * * * *}$ & $-.37^{* * * *}$ & $-.23^{* * * *}$ & -.01 & .08 & 1 & & \\
\hline 13. Assistant & -.09 & $.23^{*}$ & .15 & -.00 & -.12 & .16 & .11 & -.11 & $-.29^{* * *}$ & $-.38^{* * * *}$ & $-.62^{* * * *}$ & -.11 & 1 & \\
\hline 14. Associate & $.39^{* * * *}$ & -.03 & -.06 & .15 & .01 & .14 & -.04 & -.02 & $.45^{* * * *}$ & $-.27^{* *}$ & $.42^{* * * *}$ & -.13 & $-.44^{* *}$ & 1 \\
\hline
\end{tabular}

Notes:

$\dagger$ Statistically significant at the $90.0 \%$ level (two-tailed test)

* Statistically significant at the $95.0 \%$ level (two-tailed test)

** Statistically significant at the $99.0 \%$ level (two-tailed test)

*** Statistically significant at the $99.9 \%$ level (two-tailed test)

However, years of teaching experience seems to have little influence on the salary earned $(\mathrm{r}=.12, \mathrm{p}>.05$, two-tailed test). Another observation of Table 1 is that some of the independent variables are highly correlated. For example, the candidates' teaching experience correlates with the school tenure requirement on publications other than A journals at $0.69(\mathrm{p}<.001$, two-tailed test). The school tenure requirement on A publication also correlates with doctorate program at 0.63 ( $<<.001$, two-tailed test). Such high correlations raise the multicollinearity concern. However, further investigation with regressions found that none of the VIF (Variance Inflation Factor) values were greater than 2.5 , leading us to conclude that there was no serious multicollinearity problem (Kohler, 2002).

\section{Results Of Study 1}

As the Model 1 in Table 2 shows, when salary is only regressed on school/external factors, two factors have significant impacts on the salary level. Schools with Ph.D. programs apparently can afford more expensive offers ( $\beta=.35, \mathrm{p}<.01$, two-tailed test). Schools asking for a certain level of top tier publications as a requirement for tenure apparently have to compensate more for this work $(\beta=.34, \mathrm{p}<.01$, two-tailed test). However, surprisingly, the location of a school, if it is private or union member, and the total number of publications required for tenure seems not to impact the salary level at all [Tribunella et al., 2007]. 
We further included individual factors in the regression, as indicated by Model 2 in Table 2. With the individual factors included, both significant school/external factors lose part of their impacts on salary (Doctorate: $\beta$ $=.26, \mathrm{p}<.01$, two-tailed test; A-requirement: $\beta=.26, \mathrm{p}<.01$, two-tailed test). Apparently, having an A publication will make a huge difference in salary offers $(\beta=.43, \mathrm{p}<.001$, two-tailed test). Just having publications, if they are not in top tier journals, will not make any significant difference to salary offered $(\beta=-.13, \mathrm{p}>.05$, two-tailed test) and more surprisingly, years of teaching experience does not play an important role in determining salary level either $(\beta=.13, \mathrm{p}>.05$, two-tailed test).

Table 2- Regression Models Coefficients, Errors, and Fitness

\begin{tabular}{|c|c|c|c|}
\hline \multicolumn{4}{|c|}{ Dependent Variable = Salary } \\
\hline Regression Model & Model 1 & Model 2 & Model 3 \\
\hline \multicolumn{4}{|l|}{ School/ External Factors: } \\
\hline Year & $\begin{array}{c}-.05 \\
(1443.86)\end{array}$ & $\begin{array}{c}-.05 \\
(1225.77)\end{array}$ & $\begin{array}{c}-.10 \\
(1192.09)\end{array}$ \\
\hline Suburban & $\begin{array}{c}.15^{\dagger} \\
(3257.80)\end{array}$ & $\begin{array}{c}.16^{*} \\
(2761.51)\end{array}$ & $\begin{array}{c}.14^{*} \\
(2553.44)\end{array}$ \\
\hline Private & $\begin{array}{c}.01 \\
(3959.98)\end{array}$ & $\begin{array}{c}-.03 \\
(3409.12)\end{array}$ & $\begin{array}{c}-.03 \\
(3174.25)\end{array}$ \\
\hline Union & $\begin{array}{c}.00 \\
(4188.87)\end{array}$ & $\begin{array}{c}.01 \\
(3628.89)\end{array}$ & $\begin{array}{c}.05 \\
(3354.13)\end{array}$ \\
\hline Doctorate & $\begin{array}{c}.35^{* * *} \\
(4470.29)\end{array}$ & $\begin{array}{c}.26^{* *} \\
(3833.77)\end{array}$ & $\begin{array}{c}.10 \\
(3922.93)\end{array}$ \\
\hline A-requirement & $\begin{array}{c}.34^{* * *} \\
(1297.46)\end{array}$ & $\begin{array}{c}.26^{*} \\
(1148.18)\end{array}$ & $\begin{array}{c}.27^{* *} \\
(1066.51)\end{array}$ \\
\hline Total-requirement & $\begin{array}{c}.02 \\
(691.41)\end{array}$ & $\begin{array}{c}.08 \\
(597.13)\end{array}$ & $\begin{array}{c}.05 \\
(577.89)\end{array}$ \\
\hline \multicolumn{4}{|l|}{ Individual Factors: } \\
\hline A-pub & & $\begin{array}{c}.43^{* * * *} \\
(1136.19)\end{array}$ & $\begin{array}{c}.33^{\text {**** }} \\
(1086.17)\end{array}$ \\
\hline Other-pub & & $\begin{array}{c}-.13 \\
(427.55)\end{array}$ & $\begin{array}{c}-.11 \\
(391.48)\end{array}$ \\
\hline Teaching & & $\begin{array}{c}.13 \\
(567.62)\end{array}$ & $\begin{array}{c}.11 \\
(619.64)\end{array}$ \\
\hline \multicolumn{4}{|l|}{ Position Factors } \\
\hline Course-load & & & $\begin{array}{l}-.28^{* * * *} \\
(986.15)\end{array}$ \\
\hline Assistant & & & $\begin{array}{c}.07 \\
(3940.38)\end{array}$ \\
\hline Associate & & & $\begin{array}{c}.23^{* * *} \\
(5012.61)\end{array}$ \\
\hline \multicolumn{4}{|l|}{ Fitness Index: } \\
\hline $\mathrm{R}^{2}$ & .41 & .59 & .68 \\
\hline Adj. $R^{2}$ & .36 & .54 & .63 \\
\hline $\mathrm{F}$ & $8.51^{* * * *}$ & $12.02^{* * * *}$ & $13.08^{* * *}$ \\
\hline d.f. & $(7,87)$ & $(10,84)$ & $(13,81)$ \\
\hline$\Delta \mathrm{R}^{2}$ & & .18 & .09 \\
\hline$\Delta \mathrm{F}$ & & $12.42^{* * *}$ & $7.41^{* * * *}$ \\
\hline$\Delta$ d.f. & & 3 & 3 \\
\hline
\end{tabular}

Notes: Standard errors are in parentheses below the regression coefficients

${ }^{\dagger}$ Statistically significant at the $90.0 \%$ level (two-tailed test)

* Statistically significant at the $95.0 \%$ level (two-tailed test)

** Statistically significant at the $99.0 \%$ level (two-tailed test)

*** Statistically significant at the $99.9 \%$ level (two-tailed test) 
In Model 3 of Table 2, we included position factors as well as school/external factors and individual factors. After entering the three position factors, we found that whether a school has Ph.D. program does not matter any more $(\beta=.10, \mathrm{p}>.05$, two-tailed test), but the A publication requirements for tenure still impacts salary $(\beta=.27, \mathrm{p}$ $<.01$, two-tailed test), and candidates with A publications still apparently earn more money $(\beta=.33, \mathrm{p}<.001$, twotailed test). As expected, the compensation for associate professors was significantly higher than those for other positions $(\beta=.23, \mathrm{p}<.01$, two-tailed test).

However, perhaps surprisingly, salary seems not to reward heavier teaching loads, but to punish candidates who, if the offer is accepted, will be assuming more teaching responsibilities $(\beta=-.28, p<.01$, two-tailed test). Given the effort and time required to teach multiple classes well, it seems counterintuitive that professors who teach more be paid less, but it seems that teaching ability is less of a bargaining point than A-level publications. Perhaps in light of the changes advocated by Dennis, et al. [2006], some of which have been implemented, A-level publications will become somewhat less rare, reducing their relative strength at the bargaining table when compared to experience and skill as a teacher. Assistant professors do not distinct themselves from other positions in terms of the salary level $(\beta=.07, p>.05$, two-tailed test). Thus, Hypothesis $1 \mathrm{~b}$ is supported, with the least support for Hypothesis 1c.

\section{Results Of Study 2}

We further tested if positional factors played any mediation role between school/external and individual factors and salary. Study 1 verifies that the independent variables (institutional/external and individual factors) significantly impact salary, as shown in Model 2 in Table 2, and when including both independent variables (school/external and individual factors) and mediators (position factors) into regressions, some of the school/external and individual factors lose significance while position factors are significant.

We therefore tested if there are relationships between the independent variables (school/external and individual factors) and the mediators (position factors). To do so, we regressed all school/external and individual factors that have significant impacts on salary on each of the three position factors (i.e., Course-load, Assistant, and Associate). The results are summarized in Table 3. Model 1 and Model 2 shows that schools having Ph.D. programs have significantly lower teaching loads $(\beta=-.38, \mathrm{p}<.001$, two-tailed test). Model 3 and Model 4 show that schools with $\mathrm{Ph} . \mathrm{D}$. programs are generally more likely to offer assistant professor positions than any other positions $(\beta=.28, \mathrm{p}<.01$, two-tailed test). Model 5 and Model 6 show that none of the school/external factors relates significantly to the associate professor position. However, two individual factors, including top tier publication $(\beta=.35, \mathrm{p}<.01$, two-tailed test $)$ and teaching experience $(\beta=.27, \mathrm{p}<.1$, two-tailed test), are significantly associated with the associate professor position.

Therefore, two mediation relationships can be identified. First, the impact of one of the school/external factors - Ph.D. program - on salary is partially mediated by the position factor - course-load. Second, associate professor position mediates the relationship between candidates' top tier publications and salary. The mediation effects clearly show that schools comprehensively consider both external and individual factors to make an offer, and the salary is usually associated with the offer, even though the salary level may still be adjusted to a specific school context or a candidate's qualification. Thus, both hypothesis $2 \mathrm{a}$ and hypothesis $2 \mathrm{~b}$ are supported by the findings of Study 2.

From Study 1 and Study 2, we find that in all direct and indirect relationships associating with salary, the candidates' A journal publication shows the most impact on determining the level of salary $(.41=.33$ (direct impact) $+.23 * .35$ (indirect impact)). An obvious follow-up question is whether, when candidates have the same qualifications, their salary will be predictably different according to the sorts of schools to which they go. Therefore, we continued our investigation by conducting Study 3. In Study 3, we set out to determine if the year the job was offered, whether the institution was a private or public school, whether or not it granted Ph.D. degrees, and whether or not it was unionized moderated the relationship between the candidates' top-tier publications and salaries. 
Table 3- Mediation Tests, Coefficients, Errors, and Fitness

\begin{tabular}{|c|c|c|c|c|c|c|}
\hline \multirow{2}{*}{$\begin{array}{c}\begin{array}{l}\text { Dependent } \\
\text { Variable }=\end{array} \\
\text { Regression Model } \\
\end{array}$} & \multicolumn{2}{|c|}{ Course-Load } & \multicolumn{2}{|c|}{ Assistant } & \multicolumn{2}{|c|}{ Associate } \\
\hline & Model 1 & Model 2 & Model 3 & Model 4 & Model 5 & Model 6 \\
\hline \multicolumn{7}{|c|}{ School/External Factors: } \\
\hline Year & $\begin{array}{l}-14^{*} \\
(.12) \\
\end{array}$ & $\begin{array}{l}-.15^{\dagger} \\
(.12)\end{array}$ & $\begin{array}{l}.22^{*} \\
(.04) \\
\end{array}$ & $\begin{array}{l}.24^{* *} \\
(.03)\end{array}$ & $\begin{array}{l}-.03 \\
(.03) \\
\end{array}$ & $\begin{array}{l}-.04 \\
(.03) \\
\end{array}$ \\
\hline Suburban & $\begin{array}{c}-.03 \\
(.28) \\
\end{array}$ & $\begin{array}{l}-.03 \\
(.28) \\
\end{array}$ & $\begin{array}{c}.14 \\
(.10) \\
\end{array}$ & $\begin{array}{l}.15^{\dagger} \\
(.07) \\
\end{array}$ & $\begin{array}{l}-.00 \\
(.07) \\
\end{array}$ & $\begin{array}{l}-.00 \\
(.06) \\
\end{array}$ \\
\hline Private & $\begin{array}{c}.10 \\
(.33) \\
\end{array}$ & $\begin{array}{c}.11 \\
(.34) \\
\end{array}$ & $\begin{array}{l}-.01 \\
(.12) \\
\end{array}$ & $\begin{array}{c}.05 \\
(.09) \\
\end{array}$ & $\begin{array}{c}.18 \\
(.08) \\
\end{array}$ & $\begin{array}{c}.14 \\
(.07) \\
\end{array}$ \\
\hline Union & $\begin{array}{l}.16^{\dagger} \\
(.35)\end{array}$ & $\begin{array}{l}.16^{\dagger} \\
(.37)\end{array}$ & $\begin{array}{l}-.15 \\
(.13) \\
\end{array}$ & $\begin{array}{l}.08 \\
(.10) \\
\end{array}$ & $\begin{array}{c}.05 \\
(.09) \\
\end{array}$ & $\begin{array}{c}.04 \\
(.08) \\
\end{array}$ \\
\hline Doctorate & $\begin{array}{c}-.39^{* * * *} \\
(.38)\end{array}$ & $\begin{array}{c}.38^{* * * * *} \\
(.39)\end{array}$ & $\begin{array}{c}.19 \\
(.14) \\
\end{array}$ & $\begin{array}{l}.28^{* * *} \\
(.10)\end{array}$ & $\begin{array}{l}.28^{*} \\
(.09)\end{array}$ & $\begin{array}{c}.19 \\
(.08) \\
\end{array}$ \\
\hline A-requirement & $\begin{array}{l}-.15 \\
(.11) \\
\end{array}$ & $\begin{array}{c}-.13 \\
(.12) \\
\end{array}$ & $\begin{array}{c}.07 \\
(.04) \\
\end{array}$ & $\begin{array}{l}-.04 \\
(.03) \\
\end{array}$ & $\begin{array}{l}-.19 \\
(.03) \\
\end{array}$ & $\begin{array}{l}-.21 \\
(.02) \\
\end{array}$ \\
\hline Total-requirement & $\begin{array}{l}-.13 \\
(.06) \\
\end{array}$ & $\begin{array}{l}-.15 \\
(.06) \\
\end{array}$ & $\begin{array}{l}-21^{\dagger} \\
(.02) \\
\end{array}$ & $\begin{array}{l}-27^{* * *} \\
(.02) \\
\end{array}$ & $\begin{array}{c}.01 \\
(.01) \\
\end{array}$ & $\begin{array}{c}.06 \\
(.01) \\
\end{array}$ \\
\hline \multicolumn{7}{|l|}{ Individual Factors: } \\
\hline A-pub & & $\begin{array}{l}-.07 \\
(.11) \\
\end{array}$ & & $\begin{array}{c}-.11 \\
(.03) \\
\end{array}$ & & $\begin{array}{l}.35^{* * *} \\
(.02) \\
\end{array}$ \\
\hline Other-pub & & $\begin{array}{c}.07 \\
(.04) \\
\end{array}$ & & $\begin{array}{c}.15 \\
(.01) \\
\end{array}$ & & $\begin{array}{c}-.03 \\
(.01) \\
\end{array}$ \\
\hline Teaching & & $\begin{array}{l}.02 \\
(.06) \\
\end{array}$ & & $\begin{array}{c}-71^{* * * * *} \\
(.02)\end{array}$ & & $\begin{array}{r}.27^{\dagger} \\
(.01) \\
\end{array}$ \\
\hline \multicolumn{7}{|l|}{ Fitness Index: } \\
\hline $\mathrm{R}^{2}$ & .41 & .41 & .15 & .56 & .07 & .32 \\
\hline Adj. $\mathrm{R}^{2}$ & .36 & .34 & .08 & .51 & -.00 & .23 \\
\hline $\mathrm{F}$ & $8.50^{* * * * *}$ & $5.89^{* * * *}$ & $2.18^{*}$ & $10.88^{* \ldots * k}$ & .98 & $3.88^{\text {***** }}$ \\
\hline d.f. & $(7,87)$ & $(10,84)$ & $(7,87)$ & $(10,84)$ & $(7,87)$ & $(10,84)$ \\
\hline$\Delta \mathrm{R}^{2}$ & & .01 & & .42 & & .24 \\
\hline$\Delta \mathrm{F}$ & & .28 & & $26.69^{* * *}$ & & $9.93^{* * *}$ \\
\hline$\Delta$ d.f. & & 3 & & 3 & & 3 \\
\hline
\end{tabular}

Notes: Standard errors are in parentheses below the regression coefficients

${ }^{\dagger}$ Statistically significant at the $90.0 \%$ level (two-tailed test)

* Statistically significant at the $95.0 \%$ level (two-tailed test)

** Statistically significant at the $99.0 \%$ level (two-tailed test)

*** Statistically significant at the $99.9 \%$ level (two-tailed test)

\section{Results of Study 3}

In order to test the hypothesized moderation effect, we included four interaction items into regressions, while controlling all external, individual, and position factors, as shown in Table 4. All interaction items were mean centered to decrease the multicollinearity among the interaction items and the main-effect variables [Aiken and West 1991; Jaccard, Turrisi, and Wan 1990].

Model 1 in Table 4 includes all related school/external, individual, and position factors and it shows that when controlling everything else, the direct impact of candidates' A publications on salary is 0.33 ( $\mathrm{p}<.001$, twotailed test). Model 2 shows that after adding the first interaction item of Year and A-pub, the model fitness is improved (Adjusted R2 increases from .63 to .66) and the interaction item is negatively related to salary ( $\beta=-.21, p$ $<.01$, two-tailed test). 
Table 4- Moderation Tests, Coefficients, Errors, and Fitness

\begin{tabular}{|c|c|c|c|c|c|}
\hline \multicolumn{6}{|c|}{ Dependent Variable = Salary } \\
\hline Regression Model & Model 1 & Model 2 & Model 3 & Model 4 & Model 5 \\
\hline \multicolumn{6}{|c|}{ School/External Factors: } \\
\hline Year & $\begin{array}{c}-.10 \\
(1192.09)\end{array}$ & $\begin{array}{c}-.11 \\
(1133.91)\end{array}$ & $\begin{array}{c}-.06 \\
(1082.62)\end{array}$ & $\begin{array}{c}-.06 \\
(1187.92)\end{array}$ & $\begin{array}{c}-.10 \\
(1196.06)\end{array}$ \\
\hline Suburban & $\begin{array}{c}.14^{*} \\
(2553.44)\end{array}$ & $\begin{array}{c}.13^{*} \\
(2429.81)\end{array}$ & $\begin{array}{c}.14^{*} \\
(2294.01)\end{array}$ & $\begin{array}{c}.14^{*} \\
(2473.72)\end{array}$ & $\begin{array}{c}.14^{*} \\
(2564.03)\end{array}$ \\
\hline Private & $\begin{array}{c}.03 \\
(3174.25) \\
\end{array}$ & $\begin{array}{c}-.02 \\
(3019.54)\end{array}$ & $\begin{array}{c}.01 \\
(2879.56) \\
\end{array}$ & $\begin{array}{c}-.04 \\
(3084.27) \\
\end{array}$ & $\begin{array}{c}.03 \\
(3184.43) \\
\end{array}$ \\
\hline Union & $\begin{array}{c}.05 \\
(3354.13) \\
\end{array}$ & $\begin{array}{c}.08 \\
(3222.94) \\
\end{array}$ & $\begin{array}{c}.10 \\
(3055.07) \\
\end{array}$ & $\begin{array}{c}-.00 \\
(3412.66) \\
\end{array}$ & $\begin{array}{c}.05 \\
(3364.80) \\
\end{array}$ \\
\hline Doctorate & $\begin{array}{c}-.10 \\
(3922.93)\end{array}$ & $\begin{array}{c}.08 \\
(3739.73)\end{array}$ & $\begin{array}{c}.10 \\
(3525.26)\end{array}$ & $\begin{array}{c}.07 \\
(3816.83)\end{array}$ & $\begin{array}{c}.10 \\
(3952.15)\end{array}$ \\
\hline A-requirement & $\begin{array}{c}.27^{* * *} \\
(1066.51)\end{array}$ & $\begin{array}{c}.25^{* * *} \\
(1015.97)\end{array}$ & $\begin{array}{c}.23^{* * *} \\
(962.19)\end{array}$ & $\begin{array}{c}.25^{* * *} \\
(1035.23)\end{array}$ & $\begin{array}{c}.26^{* * *} \\
(1078.41)\end{array}$ \\
\hline Total-requirement & $\begin{array}{c}.05 \\
(577.89)\end{array}$ & $\begin{array}{c}.09 \\
(559.84)\end{array}$ & $\begin{array}{c}.06 \\
(519.42)\end{array}$ & $\begin{array}{c}.05 \\
(559.78)\end{array}$ & $\begin{array}{c}.04 \\
(584.98)\end{array}$ \\
\hline \multicolumn{6}{|l|}{ Individual Factors: } \\
\hline Teaching & $\begin{array}{c}.11 \\
(619.64)\end{array}$ & $\begin{array}{c}.15 \\
(594.03)\end{array}$ & $\begin{array}{c}.08 \\
(557.77)\end{array}$ & $\begin{array}{c}.12 \\
(600.80)\end{array}$ & $\begin{array}{c}.09 \\
(628.69)\end{array}$ \\
\hline Other-pub & $\begin{array}{c}-.11 \\
(391.48)\end{array}$ & $\begin{array}{c}-.12 \\
(372.60)\end{array}$ & $\begin{array}{c}.01 \\
(368.20)\end{array}$ & $\begin{array}{c}-.14 \\
(382.23)\end{array}$ & $\begin{array}{c}-.10 \\
(396.30)\end{array}$ \\
\hline \multicolumn{6}{|l|}{ Position Factors: } \\
\hline Course-load & $\begin{array}{c}.28^{* * * *} \\
(986.15)\end{array}$ & $\begin{array}{c}-.22^{* *} \\
(963.58)\end{array}$ & $\begin{array}{c}.35^{* * * *} \\
(906.12)\end{array}$ & $\begin{array}{c}-27^{\text {***** }} \\
(956.27)\end{array}$ & $\begin{array}{c}-28^{* * * * *} \\
(990.77)\end{array}$ \\
\hline Assistant & $\begin{array}{c}.07 \\
(3940.38)\end{array}$ & $\begin{array}{c}.09 \\
(3756.81)\end{array}$ & $\begin{array}{c}.03 \\
(3557.92)\end{array}$ & $\begin{array}{c}.05 \\
(3826.84)\end{array}$ & $\begin{array}{c}.06 \\
(3965.15)\end{array}$ \\
\hline Associate & $\begin{array}{c}.23^{* * *} \\
(5012.61)\end{array}$ & $\begin{array}{c}.21^{* * *} \\
(4782.85)\end{array}$ & $\begin{array}{c}.14^{\dagger} \\
(4640.09)\end{array}$ & $\begin{array}{c}.20^{*} \\
(4892.37)\end{array}$ & $\begin{array}{c}.22^{* * *} \\
(5047.5)\end{array}$ \\
\hline A-pub & $\begin{array}{c}.33^{* * * *} \\
(1086.17)\end{array}$ & $\begin{array}{c}.35^{* * *} \\
(1034.66)\end{array}$ & $\begin{array}{c}.13 \\
(1150.36)\end{array}$ & $\begin{array}{c}.32^{* * *} \\
(1054.89)\end{array}$ & $\begin{array}{c}.33^{* * * *} \\
(1092.20)\end{array}$ \\
\hline A-pub-Year & & $\begin{array}{c}-.21^{* * *} \\
(1039.11)\end{array}$ & & & \\
\hline A-pub-Doctorate & & & $\begin{array}{c}.36^{* * * *} \\
(1890.36)\end{array}$ & & \\
\hline A-pub-Union & & & & $\begin{array}{c}-.17^{*} \\
(2747.36)\end{array}$ & \\
\hline A-pub-Private & & & & & $\begin{array}{c}.05 \\
(1936.11)\end{array}$ \\
\hline \multicolumn{6}{|l|}{ Fitness Index: } \\
\hline $\mathrm{R}^{2}$ & .68 & .71 & .74 & .70 & .68 \\
\hline Adj. $\mathrm{R}^{2}$ & .63 & .66 & .70 & .65 & .62 \\
\hline $\mathrm{F}$ & $13.08^{* * * *}$ & $14.11^{* * * *}$ & $16.50^{* * * *}$ & $13.39^{* * * *}$ & $12.10^{* * * *}$ \\
\hline d.f. & $(13,81)$ & $(14,80)$ & $(14,80)$ & $(14,80)$ & $(14,80)$ \\
\hline$\Delta \mathrm{R}^{2}$ & & .04 & .07 & .02 & .00 \\
\hline$\Delta \mathrm{F}$ & & $9.59^{* *}$ & $20.37^{* * * *}$ & $6.33^{*}$ & .49 \\
\hline$\Delta$ d.f. & & 1 & 1 & 1 & 1 \\
\hline
\end{tabular}

Notes: Standard errors are in parentheses below the regression coefficients

${ }^{\dagger}$ Statistically significant at the $90.0 \%$ level (two-tailed test)

* Statistically significant at the $95.0 \%$ level (two-tailed test)

** Statistically significant at the $99.0 \%$ level (two-tailed test)

*** Statistically significant at the $99.9 \%$ level (two-tailed test)

Therefore, from 2003 to 2006, the reward for a constant number of A-publications is decreasing. In Model 3 , we added another interaction item - the interaction between Doctorate and A-pub - into regression. Analysis shows that schools with Ph.D. degrees tend to be more generous at giving higher salaries to candidates with top-tier 
publications ( $\beta=.36, \mathrm{p}<.001$, two-tailed test). Third, Model 4 shows that the interaction item of Union and A-pub has a negative impact on salary $(\beta=-.17, \mathrm{p}<.05$, two-tailed test), indicating that schools with unions tend to give less salary as a reward for A-publications than do schools without unions. Last but not least, the interaction item of Private and A-pub seems not influence on salary level $(\beta=.05, p>.05$, two-tailed test), as Model 5 in Table 4. This may indicate that there is no difference between private and public schools in the rewards for top-tier publications. We thus found support for hypotheses $3 \mathrm{a}, 3 \mathrm{~b}$, and $3 \mathrm{c}$, but not for hypothesis $3 \mathrm{~d}$.

\section{CONCLUSIONS, LIMITATIONS AND SUGGESTIONS FOR FUTURE RESEARCH}

\section{Conclusions}

Based on the findings of these three studies, we are able to build a model to illustrate how MIS faculty salary offers are determined (see Figure 1).

Figure 1- Model of MIS Faculty Salary Offers

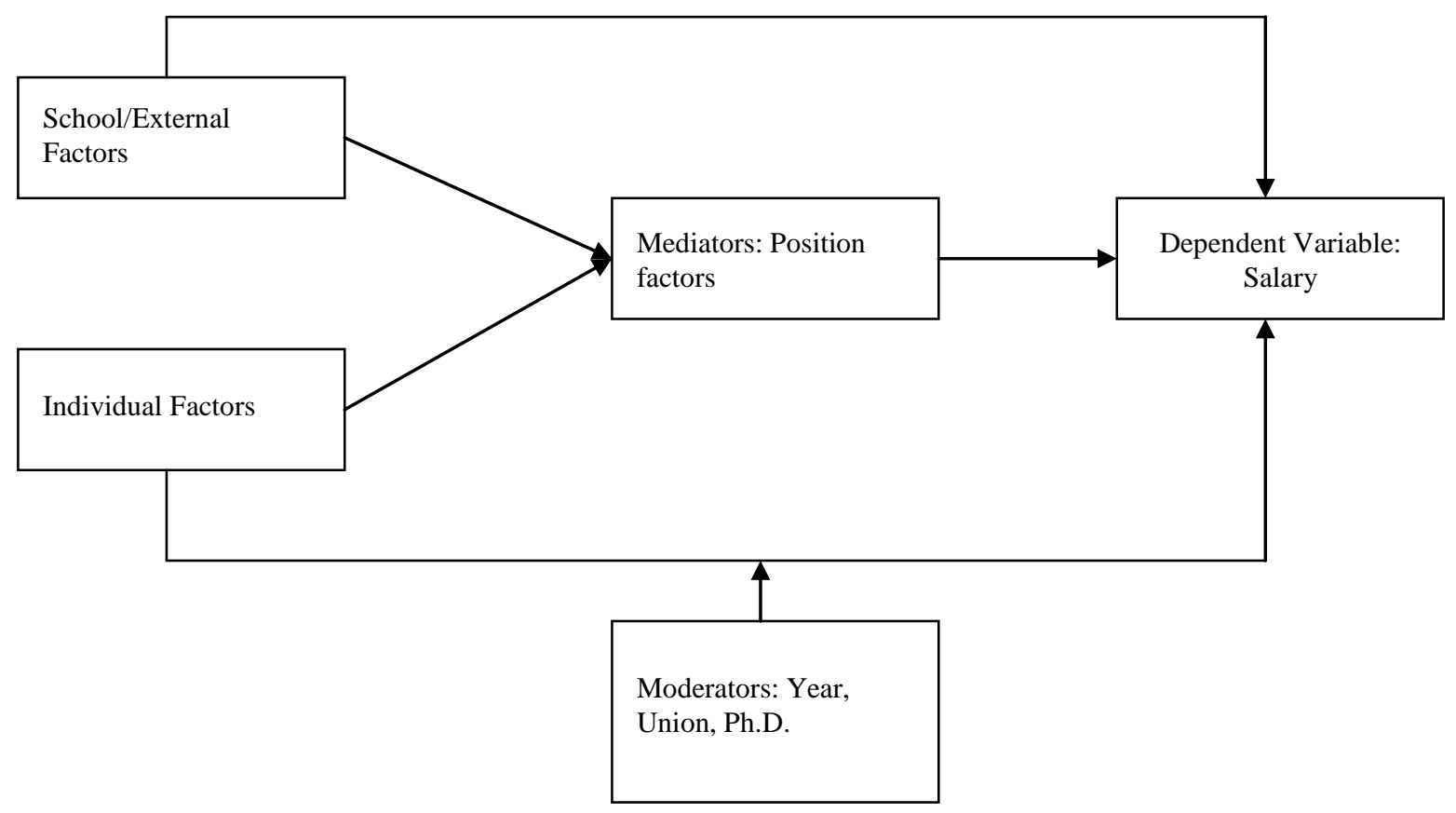

Figure 1, above, presents a model of offered salary based on our results. One of the most obvious conclusions to be drawn from these findings is that, since individual traits are the major factor driving salary, faculty members who are salary-focused should not avoid "lower-tier" institutions for that reason. Rather than concerning themselves with institutional traits such as whether it is a public or private institution, MIS faculty members should focus on developing those traits in themselves that lead to the sorts of offers they would find attractive. Professor Galleta's data does not include fuzzier characteristics such as personality or collegiality, which would be very hard to measure in this survey, but which might be another significant factor in determining how strongly an institution might want to pursue a prospective new hire [c.f., Larsen and Neely, 2000]

Similarly, institutions which are not known as research powerhouses seem able to match the offers made by the top institutions - at least, those that pursue the candidates with higher market value are generally able to follow through with offers comparable to those of the powerhouses when they choose to. Institutions that have traditionally not been strong on research, but that would like to develop this area may take note that salaries for such faculty are 
typically somewhat higher than they may be used to offering initially, but that they are clearly capable of competing for these candidates.

Another conclusion to be drawn is that the mediating role of position factors implies that the precise nature of the position is negotiable. Institutions may hire new faculty as associate professors (either with or without tenure) in order to justify a salary commensurate with their qualifications - or, possibly, an institution might offer a higher rank (and tenure) to offset a somewhat lower salary or a higher teaching load. Flexibility as to the nature of the position may thus be an advantage for both candidates and institutions, though as the power to reshape the position ultimately lies on the institution side, it is more likely to be a means by which institutions might attract desirable candidates. For example, consider a middle-tier school seeking to attract status-conscious, ambitious junior faculty to augment its research strength. This school might consider a variation on the Harvard Business School approach to promotion and tenure, under which assistant professors are considered for promotion to associate after four years instead of after six - but still do not get considered for tenure until they have been at the school for the full six years.

It is also worth noting that MIS professionals were better able to identify the primary driver of MIS faculty salary offers - accomplishments, here operationalized as top-tier publications - than were MIS faculty. This may be because they have the benefit of an outside perspective untainted by the lore and myths of the profession - such as the widely-held opinion within the field that private institutions pay more. However, if this is the case, it suggests that MIS professionals might benefit from a scientific inquiry into the factors influencing their own salaries, and that they might be somewhat surprised by the findings of such a study.

These findings also suggest that faculty members seeking jobs and those seeking to hire them may want to do their homework before starting the process - starting by visiting the AIS website and reading Professor Galleta's report. Chairs of doctoral programs and advisors may also wish to advise their doctoral students to study the report - and to complete the survey when their time comes. This will give their students considerable advantage both in terms of understanding the market when they are in the process and in terms of knowing how to prepare for it as they pursue their studies.

\section{Limitations And Suggestions For Future Research}

One of the major limitations of this study is that we have focused entirely on one aspect of the job offer: salary. This is clearly an important component of any job, but other aspects may be equally or perhaps even more important. We were unable, for example, to address the question of whether the individual candidate preferred a more teaching-oriented position or a more research-oriented one. Similarly, we were unable to address the question of geographic preferences - did the candidate prefer to live in a particular geographic region? Did the candidate prefer to work at a rural, a suburban, or an urban institution?

These preferences could potentially influence the salary component of the job offer, though we lack the data to address this question. Knowing these preferences would offer a better understanding of job offers and would allow a study like this one to investigate more comprehensively job offers, rather than focusing on just the salary component. Thus, we would suggest that Dr. Galletta consider adding questions regarding what the candidate wanted in a job, perhaps also including a rank ordering of these factors and salary. Having this data would allow future researchers to develop a much more nuanced view of the job offer process.

Additionally, the Galletta website has a prescribed listing of journals that constitute top tier journals. This is not necessarily the same listing of journals found in other studies (e.g. Dennis 2006, Hardgrave and Walstrom, 1997). The journals listed in the Galletta survey include Communications of the ACM and IEEE (Institute of Electrical and Electronics Engineers) journals, journals that are not necessarily premier journals for top research schools. Thus, another modification to the Galletta survey would be to tailor the list of top tier journals to include only those journals that a top research school would classify as A journals. Having a tighter A journal list would allow future researchers to better evaluate the impact of A journal publications on the job offer process. 


\section{REFERENCES}

1. Anonymous. (2005a). AAUP Survey: Faculty Salaries Fail to Keep Pace with Rate of Inflation, Black Issues in Higher Education, 22(7), p. 23.

2. Anonymous. (2005b). Study: Inflation Outpaces Teacher Salary Growth in More Than 40 States, Diverse Issues in Higher Education, 22(23), p. 9.

3. Aiken, L.S., and West, S.G. (1991). Multiple Regression: Testing and Interpreting Interactions. Newbury Park, Calif.: Sage Publications.

4. Bratsberg, B., Ragan Jr, J. F., and Warren, J. T. (2003). Negative returns to seniority: New evidence in academic markets, Industrial \& Labor Relations Review, 56(2), p. 306.

5. Castle, D. S. (2005). Estimating Seniority Effects in Faculty Salary Studies: Measurement and Model Specification, Public Personnel Management, 34(4), pp. 377-384.

6. Dennis A.R., Valacich, J.S., Fuller, M.A., and Schneider, C. (2006) Research Standards for Promotion and Tenure in Information Systems, MIS Quarterly, 30(1), pp. 1-12.

7. Formby, J. P., and Hoover, G. A. (2002). Salary Determinants of Entry-level Academic Economists and the Characteristics of Those Hired on the Tenure Track, Eastern Economic Journal, 28(4), pp. 509-522.

8. Gibson, C.B., and Birkinshaw, J. (2004). The Antecedents, Consequences, and Mediating Role of Organizational Ambidexterity, Academy of Management Journal. 47 (2), pp. 209-226.

9. Hardgrave, B. C., and Walstrom, K. A. (1997). Forums for MIS Scholars, Communications of the ACM, 40 (11), pp. 119-124.

10. Hobbs, B. K., Weeks, H. S., and Finch, J. H. (2005). Estimating the Mark-to-Market Premium Required to Fill Vacant Business School Faculty Lines: The Case of Finance, Journal of Education for Business, 80(5), pp. $253-258$.

11. Jaccard, J., Turrisi, R., and Wan, C.K. (1990). Interaction Effects in Multiple Regression. Thousand Oaks: Sage Publications.

12. Judd, C. M., E. R. Smith, and L. H. Kidder. (1991) Research Methods in Social Relations, London, UK: Holt, Rinehart and Winston.

13. Kirk, J. J. (1996). Predictors of Salary Level for HRD Academes, Human Resource Development Quarterly, 7(4), pp. 359-367.

14. Kohler, Heinz (2002). Statistics for Business and Economics, South-Western Tomson, London, UK.

15. Larsen, K.R.T. and M.P. Neely. (2000) Profiles of MIS Doctoral Candidates: Ideals and Reality, The DATABASE for Advances in Information Systems, 31(3), pp. 64-89.

16. Nagowski, M. P. (2006). Associate Professor Turnover at America's Public and Private Institutions of Higher Education, American Economist, 50(1), pp. 69-79.

17. Podsakoff, P.M., and Organ, D.W. (1986). Self-reports in Organizational Research: Problems and Prospects, Journal of Management, 12(4), pp. 531-545.

18. Smallwood, S. (2005). Faculty Salaries Rose 2.8\%, but Failed to Keep Pace With Inflation for the First Time in 8 Years, The Chronicle of Higher Education, 51(33), p. 12.

19. Stock, W. A., and Siegfried, J. J. (2001). So you want to earn a Ph.D. in economics: How much do you think you'll make? Economic Inquiry, 39(2), pp. 320-335.

20. Tribunella, T., M. P. Neely, and Hull, C. E. (2007). An Analysis of the Determinants of MIS Faculty Salary Offers, Review of Business Information Systems. 11(1), pp. 25-36.

21. Wilson, R. (2004). Faculty Salaries Rise 2.1\%, the Lowest Increase in 30 Years, The Chronicle of Higher Education, 50(33), p. 12.

22. Zoghi, C. (2003). Why Have University Professors Done So Badly, Economics of Education Review. 22(1), pp. $45-57$. 
NOTES 